\title{
Violência velada e revelada contra idosos em Minas Gerais-Brasil: análise de denúncias e notificações
}

\author{
Veiled and revealed violence against the elderly in Minas Gerais- \\ Brazil: analysis of complaints and notifications \\ Regina da Cunha Rocha', Maria da Conceição Juste Werneck Côrtes ${ }^{\mathbf{2}}$, Elizabeth Costa Dias $\mathbf{3}$, \\ Eliane Dias Gontijo 4
}

DOI: $10.1590 / 0103-110420185406$

1 Secretaria Municipal de Saúde de Belo Horizonte - Belo Horizonte (MG), Brasil.

Orcid: https://orcid. org/0000-0002-85450021

regina.crocha@pbh.gov.br

2 Universidade Federal de Minas Gerais (UFMG),

Programa de Pós-

Graduação de Promoção de Saúde e Prevenção da Violência (PSPV) - Belo Horizonte (MG), Brasil. Orcid: https://orcid. org/0000-0002-37492841

cwerneck5@gmail.com

3 Universidade Federal de Minas Gerais (UFMG), Programa de Pós-

Graduação de Promoção de Saúde e Prevenção da Violência (PSPV) - Belo Horizonte (MG), Brasil. Orcid: https://orcid. org/0000-0003-17081014

bethdias@medicina.ufmg.br

${ }^{4}$ Universidade Federal de Minas Gerais (UFMG)

Programa de Pós-

Graduação de Promoção de Saúde e Prevenção da violência (PSPV) - Belo

Horizonte (MG), Brasil.

Orcid: https://orcid

org/0000-0002-7518-

$898 \mathrm{X}$

egontij05@terra.com.br
RESUMO O estudo caracterizou a violência contra idosos, a partir de denúncias e notificações registradas no Disque Direitos Humanos e Sistema de Informação de Agravos de Notificações (Sinan) em 2011 e 2012. Ocorreram 2.337 denúncias (13\%) e 1.886 notificações (5\%) contra idosos. A taxa de denúncia aumentou três vezes, e a de notificação duplicou no período. Verificou-se que as vítimas, na maioria, são mulheres, agredidas no domicílio (90\%) por conhecidos (90\%), com predomínio (80\%) da tipologia por negligência/abandono, nas duas fontes. $\mathrm{O}$ aprimoramento da vigilância contribui para revelar a violência em todos os seus disfarces, efetivar políticas públicas e estimular reflexão/ação da sociedade.

PALAVRAS-CHAVE Violência. Idosos. Vigilância epidemiológica. Notificação.

ABSTRACT The study aims to characterize the violence against the elderly, from complaints and notifications recorded in Dial Human Rights, and Information System for Notifiable Diseases (Sinan) in 2011 and 2012. 2337 complaints (12.7\%) and 1886 notifications (5.3\%) against the elderly were found. The complaint rate increased 3 times and the notification rate increased 2 times in a year. It was verified that the majority of the victims were women, beaten at home (90\%) by known people (90\%), with predominance (80\%) of typology by neglect/ abandonment in both sources. The improvement of surveillance contributes to reveal the violence in all its guises, to effect public policy, and stimulate the reflection/action of society.

KEYWORDS Violence. Elderly. Epidemiologic surveillance. Notification. 


\section{Introdução}

A violência contra a pessoa idosa é um fenômeno crescente, de grande complexidade que se revela nas formas como a sociedade organiza suas relações de classe, de gênero, grupos etários e de como o poder é exercido.

O envelhecimento populacional, fenômeno que decorre da redução da fecundidade, da queda nas taxas de mortalidade e do aumento da expectativa de vida, constitui-se em um grande desafio para a saúde pública'. Embora o aumento da longevidade e melhoria da qualidade de vida sejam uma conquista inegável para a sociedade, a fragilidade, as modificações fisiológicas e certas patologias típicas da terceira idade tornam a pessoa idosa mais susceptível às violências ${ }^{2}$, criando uma demanda maior para os serviços de saúde decorrente do aumento da morbidade, óbitos, traumas físicos e psicológicos ${ }^{3}$.

Nesse sentido, obedecendo às recomendações do Informe Mundial da Organização Mundial da Saúde - OMS (2002) sobre violência e saúde, em 2006, o Ministério da Saúde implantou o Sistema de Vigilância de Violência e Acidentes (Viva) ${ }^{3,4}$ - que, a partir de 2009, passou a integrar o Sistema de Informação de Agravos de Notificação versão net (Sinan Net) -, que tem por objetivo fornecer informações sobre violência doméstica, sexual e outros tipos de violência (psicológica/moral; financeira/econômica; tortura; tráfico de pessoas; trabalho infantil; negligência/abandono; intervenção por agente legal; autoprovocada) contra mulheres e homens de todas as idades ${ }^{5}$.

Os registros das fichas de notificação/investigação individual de violência doméstica, sexual e/ou outras violências que alimentam o Sinan Net são feitos, principalmente, pelos serviços de saúde, instituições de longa permanência para idosos, centros de referências para vítimas de violências, centros de convivências.

A violência contra idosos é um problema de importância crescente no País, mas de notificação compulsória recente. Desde 2003, o Estatuto do Idoso ${ }^{6}$ determina que os casos suspeitos ou confirmados de maus-tratos contra idosos sejam obrigatoriamente comunicados. No ano de 2011, outros dispositivos legais vieram contribuir para o incremento da notificação no Brasil: a inclusão da violência na relação de doenças e agravos de notificação compulsória, em todos os serviços de saúde do território nacional7; a notificação compulsória para os serviços de saúde públicos e privados acerca da violência praticada contra idosos e a exigência da comunicação à vigilância epidemiológica. Entretanto a formalização de uma política não é capaz de fornecer garantias de proteção, pois, para a consolidação de um direito, é necessária a sua apropriação pela população. Nessa perspectiva, a violência contra idosos se nutre de fatos políticos, econômicos e culturais traduzidos nas relações cotidianas que, por serem construídos pela sociedade, em determinadas circunstâncias, podem também ser desconstruídos e superados ${ }^{\mathbf{8}, 9}$. Ademais, os significados atribuídos à violência e a identificação dos idosos que se encontram em situação de vulnerabilidade influenciam nas condutas dos profissionais de saúde e da própria sociedade para informar a agressão ${ }^{10}$.

As denúncias e notificações contribuem para o conhecimento da dinâmica e dimensionamento do fenômeno" ${ }^{11}$. O Disque Direitos Humanos - Disque 100 se constitui em um canal de comunicação da sociedade com o Poder Público - Ouvidoria Nacional de Direitos Humanos - visando à resolução de conflitos quando há suspeita de violações de direitos. O serviço de atendimento telefônico gratuito funciona 24 horas todos os dias da semana. As denúncias são analisadas e encaminhadas aos órgãos responsáveis. Por sua natureza de instância de diálogo e registro de manifestações da população, o Disque 100 tem se consolidado como importante instrumento de dados estatísticos sobre violações de direitos humanos, incluindo a violência contra idosos ${ }^{\mathbf{1 2}}$. Já o Sinan Net Viva fornece informações sobre violência doméstica ${ }^{12}$, sexual e outros tipos de violência contra mulheres e homens de todas as idades, por meio de preenchimento de fichas de notificação da violência ${ }^{13}$. 
Apesar disso, a violência contra a pessoa idosa tem sido pouco informada, permanecendo velada no contexto de segredo ou conluio familiar ${ }^{\mathbf{1 4}}$. Entre os entraves ao ato de notificar, estão: a precariedade de recursos públicos para apurar e dar alguma solução às situações denunciadas, a falta da retaguarda de uma rede de proteção, o desconhecimento do fluxo de notificação, bem como o pouco preparo técnico e emocional de profissionais para identificação dos $\operatorname{casos}^{15}$. A multiplicidade e a falta de integração das fontes de informação e as altas taxas de sub-registro são também desafios a serem superados, visando à obtenção de estimativas da ocorrência que auxiliem na vigilância e assistência para essa população.

Em que pese o rápido e acelerado envelhecimento populacional brasileiro, a escassez de informação e consequente subdimensionamento do fenômeno reforçam a importância de analisar e divulgar o perfil da violência contra idosos, identificado a partir de denúncias e/ ou notificações em diferentes estados e municípios brasileiros. Nesse sentido, este estudo buscou descrever as denúncias captadas pelo Disque Direitos Humanos e as notificações de violência registradas no Sinan Net, no estado de Minas Gerais, nos anos de 2011 e 2012.

\section{Métodos}

Estudo descritivo de abrangência estadual, realizado com dados obtidos no Sistema Nacional do Disque Direitos Humanos - Disque 100 e no Sinan Net de notificações de violência doméstica, sexual e/ou outras violências contra indivíduos com idade igual ou maior de 60 anos, registrados no período de $1^{\circ}$ de janeiro de 2011 a 31 de dezembro de 2012, em Minas Gerais.

As denúncias e notificações foram analisadas segundo a tipologia da violência (física, psicológica/moral, negligência/abandono, sexual, financeiro/econômica, autoprovocada); características sociodemográficas da vítima (sexo, idade, cor); características do agressor (relação de parentesco com a vítima) e local de ocorrência.
$\mathrm{Na}$ análise dos dados do Disque 100, foi feita distribuição de frequências e cálculo de taxas das variáveis relacionadas com o sexo das vítimas, tipologias das violências, relação com agressor e local de ocorrência.

A análise do Sinan incluiu distribuição da frequência das notificações por tipos, isoladamente e associados, segundo as mesorregiões de Minas Gerais. Para comparar a distribuição do tipo de violência, da relação da vítima com o agressor, cor e local de ocorrência entre sexo e faixa etária (60 a 69, 70 a 79, 80 anos ou mais), foi realizado o teste Qui-Quadrado ou teste Exato de Fisher.

A associação entre características da vítima e do agressor e os tipos de notificação de violência mais frequentes foi calculada por meio das razões de chances e seus respectivos intervalos de confiança. As variáveis que se mantiveram com nível de significância $\mathrm{p}<$ 0,20 foram incluídas no modelo de Regressão Logística. O nível de significância adotado no trabalho foi de $5 \%$. As notificações das violências contra idosos foram analisadas pelo programa SPSS 20.0 (Statistical Package for the Social Sciences).

\section{Resultados}

O estudo caracterizou a violência contra idosos em Minas Gerais, a partir de denúncias e notificações registradas no Disque 100 e Sinan em 2011 e 2012. Verificou-se 2.337 denúncias (12,7\%) e 1.886 notificações (5,3\%) contra idosos, representado aumento de $75 \%$ no número total de denúncias de violência, sendo $180 \%$ de idosos. As notificações ao Sinan aumentaram em $59 \%$, passando de aproximadamente 14 mil para 22 mil. Em 2012, a violação de direitos dos idosos representou $16 \%$ do total de denúncias e $6 \%$ de todas as notificações.

\section{Análise das denúncias}

No período investigado, a taxa de denúncias passou de 26 por cem mil idosos em 2011, para 
70 por cem mil idosos em 2012, representando incremento de 2,7 vezes em um ano. Em cerca de $70 \%$ dos casos denunciados, as vítimas são mulheres, a quase totalidade das agressões (90\%) ocorreu no domicílio, cometidas pelo(a) filho(a) em 66,5\% das denúncias feitas em 2011 e $51,2 \%$ daquelas captadas pelo Disque 100 , no ano de 2012. Apenas 10\% das agressões foram cometidas por desconhecidos.
Em relação à tipologia, predominam a negligência/abandono, seguida da violência psicológica/moral e financeira/econômica, que juntas responderam por cerca de $80 \%$ das agressões denunciadas. A negligência/ abandono vem aumentando e, em 2012, passou a representar mais de um terço das denúncias (tabela 1).

Tabela 1. Denúncias de violências contra idosos por sexo, tipologia, local de ocorrência e relação com agressor taxas (100.000). Minas Gerais, 2011-2012

\begin{tabular}{|c|c|c|c|c|c|c|c|}
\hline \multirow[b]{2}{*}{ Categorias } & \multirow[b]{2}{*}{ Variáveis } & \multicolumn{3}{|c|}{ Ano 2011} & \multicolumn{3}{|c|}{ Ano 2012} \\
\hline & & $\mathbf{N}$ & $\%$ & $\begin{array}{l}\text { Taxa por } \\
100.000\end{array}$ & $\mathbf{N}$ & $\%$ & $\begin{array}{l}\text { Taxa por } \\
100.000\end{array}$ \\
\hline Total de idosos vitimizados/ano & 60 anos e mais & 614 & & 26 & 1.723 & & 70 \\
\hline \multirow[t]{3}{*}{ Sexo: total de registros/ano } & Feminino & 628 & 69,2 & 48 & 1.952 & 67,3 & 144 \\
\hline & Masculino & 279 & 30,8 & 26 & 950 & 32,7 & 86 \\
\hline & Total & 907 & & & 2.902 & & \\
\hline \multirow[t]{7}{*}{ Tipo de violência } & Física & 283 & 20,2 & 12 & 584 & 16,7 & 24 \\
\hline & Psico/moral & 390 & 27,9 & 16 & 1.058 & 30,2 & 43 \\
\hline & Sexual & 10 & 0,7 & - & 25 & 0,7 & 1 \\
\hline & Financeira/econômica & 318 & 22,7 & 13 & 642 & 18,3 & 26 \\
\hline & Negligência/abandono & 358 & 25,6 & 15 & 1.118 & 31,9 & 45 \\
\hline & Outra & 39 & 2,8 & 2 & 74 & 2,1 & 3 \\
\hline & Total & 1.398 & & & 3.501 & & \\
\hline \multirow[t]{6}{*}{ Local de ocorrência } & Residência & 854 & 90,6 & 36 & 2.787 & 89,7 & 113 \\
\hline & Via pública & 25 & 2,7 & 1 & 90 & 2,9 & 4 \\
\hline & Outros & 23 & 2,4 & 1 & 182 & 5,9 & 7 \\
\hline & Habitação coletiva & 40 & 4,2 & 2 & 47 & 1,5 & 2 \\
\hline & Escola & 1 & 0,1 & - & 0 & 0,0 & 0 \\
\hline & Total & 943 & & & 3.106 & & \\
\hline \multirow[t]{6}{*}{ Relação / vínculo agressor } & Filho(a) & 467 & 66,5 & 2 & 1.465 & 51,2 & 59 \\
\hline & Outros vínculos & 45 & 6,4 & 2 & 804 & 28,1 & 33 \\
\hline & Própria pessoa & 2 & 0,3 & - & 4 & 0,1 & 0 \\
\hline & Desconhecido(a) & 75 & 10,7 & 3 & 287 & 10,0 & 12 \\
\hline & Cônjuge & 20 & 2,8 & 1 & 87 & 3,0 & 4 \\
\hline & Amigo/conhecido & 10 & 1,4 & - & 17 & 0,6 & 1 \\
\hline
\end{tabular}


Tabela 1. (cont.)

\begin{tabular}{|c|c|c|c|c|c|c|c|}
\hline \multirow[t]{8}{*}{ Relação / vínculo agressor } & Cuidador(a) & 36 & 5,1 & 2 & 58 & 2,0 & 2 \\
\hline & Irmão(ã) & 29 & 4,1 & 1 & 87 & 3,0 & 4 \\
\hline & Ex-cônjuge & 5 & 0,7 & - & 11 & 0,4 & 0 \\
\hline & Mãe & 3 & 0,4 & - & 23 & 0,8 & 1 \\
\hline & Namorado(a) & 0 & 0,0 & - & 4 & 0,1 & 0 \\
\hline & Pai & 5 & 0,7 & - & 7 & 0,2 & 0 \\
\hline & Patrão/chefe & 5 & 0,7 & - & 6 & 0,2 & 0 \\
\hline & Total & 702 & & & 2.860 & & \\
\hline
\end{tabular}

Fonte: SDH, $2013^{12}$.

\section{Análise das notificações}

A taxa de notificação passou de 25 por cem mil idosos em 2011 para 52 por cem mil idosos em 2012, representando aumento de 2,1 vezes em um ano.

A análise das notificações revela que quase um terço dos idosos (27\%) foram vítimas de mais de um tipo de violência. Predominou a violência física que vitimou $77,5 \%$ dos idosos, sendo notificada isoladamente $(55,5 \%)$ ou associada a outras violências (22,0\%). Destaca-se a associação da violência física com a psicológica em $13,5 \%$, seguida da negligência em $5,9 \%$ e da psicológica em $4,9 \%$ das notificações (tabela 2).

As violências físicas, torturas e

Tabela 2. Variáveis notificadas - tipologia, relação com agressor, raça/cor, local de ocorrência - por sexo e faixa etária. Minas Gerais, $2011-2012$

\begin{tabular}{|c|c|c|c|c|c|c|c|c|c|c|c|c|c|}
\hline \multirow[t]{3}{*}{ Categoria } & \multirow[t]{3}{*}{ Variável } & \multicolumn{5}{|c|}{ Sexo } & \multicolumn{7}{|c|}{ Faixa Etária } \\
\hline & & \multicolumn{2}{|c|}{ Feminino } & \multicolumn{2}{|c|}{ Masculino } & \multirow[b]{2}{*}{$\mathrm{p}$} & \multicolumn{2}{|c|}{60 a 69} & \multicolumn{2}{|c|}{70 a 79} & \multicolumn{3}{|c|}{$\geq 80$} \\
\hline & & & $\%$ & $\mathbf{N}$ & $\%$ & & $\mathbf{N}$ & $\%$ & $\mathbf{N}$ & $\%$ & $\mathbf{N}$ & $\%$ & $\mathrm{p}$ \\
\hline \multirow[t]{8}{*}{ Tipologia } & Física & 731 & 75,8 & 702 & 87,9 & & 855 & 86,5 & 412 & 80,6 & 166 & 62,90 & 0,00 \\
\hline & Psicológica & 362 & 39,8 & 155 & 21,7 & 0,00 & 279 & 31,3 & 140 & 29,0 & 98 & 39,40 & 0,02 \\
\hline & Tortura & 34 & 3,8 & 44 & 6,2 & 0,03 & 35 & 4,0 & 32 & 6,7 & 11 & 4,50 & 0,08 \\
\hline & Sexual & 54 & 6,1 & 2 & 0,3 & 0,00 & 29 & 3,3 & 14 & 3,0 & 13 & 5,30 & 0,23 \\
\hline & Financeira & 67 & 7,5 & 36 & 5,1 & 0,05 & 44 & 5,0 & 28 & 5,8 & 31 & 12,80 & 0,00 \\
\hline & Negligência & 126 & 13,8 & 75 & 10,5 & 0,04 & 33 & 3,7 & 82 & 16,7 & 86 & 34,10 & 0,00 \\
\hline & Autoprovocada & 111 & 12,7 & 115 & 16,9 & 0,02 & 151 & 17,5 & 60 & 13,1 & 15 & 6,40 & 0,00 \\
\hline & Outras & 52 & 5,8 & 41 & 5,7 & 0,97 & 66 & 7,3 & 19 & 4,0 & 8 & 3,30 & 0,01 \\
\hline \multirow[t]{3}{*}{ Relação com o agressor } & Pai \Padrasto & 5 & 0,6 & 11 & 1,9 & 0,03 & 7 & 0,9 & 3 & 0,7 & 6 & 2,8 & 0,07 \\
\hline & Mãe & 20 & 2,6 & 1 & 0,2 & 0,00 & 10 & 1,4 & 7 & 1,7 & 4 & 1,9 & 0,72 \\
\hline & Cônjuge \Ex & 155 & 19,4 & 68 & 11,6 & 0,00 & 157 & 20,6 & 41 & 10,0 & 25 & 11,7 & 0,00 \\
\hline
\end{tabular}




\begin{tabular}{|c|c|c|c|c|c|c|c|c|c|c|c|c|c|}
\hline \multirow[t]{10}{*}{ Relação com o agressor } & Namorado(a) & 17 & 2,2 & 7 & 1,2 & 0,18 & 18 & 2,5 & 4 & 1,0 & 2 & 1,0 & 0,15 \\
\hline & Filho & 251 & 31,1 & 132 & 22,1 & 0,00 & 167 & 21,9 & 129 & 30,6 & 87 & 39,5 & 0,00 \\
\hline & Desconhecido & 78 & 10,0 & 133 & 22,5 & 0,00 & 114 & 15,2 & 66 & 16,1 & 31 & 14,6 & 0,88 \\
\hline & Irmão & 28 & 3,6 & 22 & 3,9 & 0,83 & 32 & 4,4 & 14 & 3,5 & 4 & 1,9 & 0,23 \\
\hline & Conhecido & 104 & 13,3 & 113 & 19,3 & 0,00 & 137 & 18,3 & 57 & 14,0 & 23 & 10,8 & 0,02 \\
\hline & Cuidador & 18 & 2,3 & 12 & 2,1 & 0,80 & 4 & 0,5 & 14 & 3,5 & 12 & 5,7 & 0,00 \\
\hline & Institucional & 10 & 1,3 & 4 & 0,7 & 0,42 & 7 & 1,0 & 4 & 1,0 & 3 & 1,4 & 0,71 \\
\hline & Policial & 3 & 0,4 & 6 & 1,1 & 0,18 & 5 & 0,7 & 2 & 0,5 & 2 & 1,0 & 0,81 \\
\hline & Própria Pessoa & 77 & 9,8 & 83 & 14,4 & 0,01 & 109 & 14,5 & 41 & 10,1 & 10 & 4,8 & 0,00 \\
\hline & Outros & 161 & 20,7 & 86 & 15,2 & 0,01 & 108 & 14,7 & 91 & 22,8 & 48 & 23,3 & 0,00 \\
\hline \multirow[t]{3}{*}{ Raça/cor } & Amarela \Indígena & 14 & 1,6 & 12 & 1,7 & 0,99 & 13 & $1,5 \%$ & 12 & 2,6 & 1 & 0,4 & $0,10^{*}$ \\
\hline & Preta \Parda & 378 & 43,1 & 289 & 41,6 & 0,61 & 388 & 44,5 & 188 & 40,6 & 91 & 38,2 & 0,14 \\
\hline & Branca & 486 & 55,4 & 393 & 56,6 & 0,65 & 470 & 54,0 & 263 & 56,8 & 146 & 61,3 & 0,11 \\
\hline \multirow[t]{4}{*}{ Local de ocorrência } & Habitação Coletiva & 8 & 0,9 & 6 & 1,0 & 1,00 & 2 & 0,2 & 7 & 1,5 & 5 & 2,0 & $0,00 a$ \\
\hline & Residência & 767 & 84,5 & 473 & 70,5 & 0,00 & 641 & 74,7 & 382 & 81,8 & 217 & 85,4 & 0,00 \\
\hline & Via Pública & 93 & 10,2 & 120 & 17,9 & 0,00 & 141 & 16,4 & 52 & 11,1 & 20 & 7,9 & 0,00 \\
\hline & Outros & 40 & 4,4 & 72 & 10,7 & 0,00 & 74 & 8,6 & 26 & 5,6 & 12 & 4,7 & 0,03 \\
\hline
\end{tabular}

Fonte: Sinan-201313

*Total acima de 100\% pois a análise é de eventos e não de notificações - vários eventos podem ocorrer na mesma notificação/idoso.

autoprovocadas mostraram-se associadas ao sexo masculino, enquanto as violências psicológicas e sexuais, financeiras (valor-p=0,05) e negligências predominam no sexo feminino. A violência física e a negligência ocorreram mais em idosos entre 60 e 79 anos; enquanto a violência psicológica e a financeira, naqueles com idade igual ou superior a 80 anos.

Em relação ao vínculo com o agressor, mulheres foram mais agredidas por familiares ou conhecidos, enquanto os homens foram vitimados por desconhecido. Idosos acima de 70 anos sofreram mais violências cometidas pelos filhos. A proporção de idosos agredidos por um cuidador foi maior naqueles com mais de 80 anos se comparado aos idosos na faixa dos 60-79 anos. Não se observa associação em relação à cor da vítima e sua faixa etária. Quanto ao local da agressão, a residência e a habitação coletiva foram mais frequentes em idosos com mais de 70 anos. Na faixa etária de 60-69 anos, foi maior a proporção de idosos vitimizados em via pública.

A violência física foi preponderante no idoso do sexo masculino (OR=2,3 IC95\% 1,78$2,99)$ e na faixa de 60-69 anos (OR=3,8 IC95\% 2,79-5,17). A violência física tem maior chance de ocorrer fora do domicílio (OR=2,94 IC95\% $1,98-4,35)$ e de ser cometida por agressor, sem vínculo familiar (OR=1,61 IC95\% 1,222,12), mas após consumo de bebida alcoólica (OR=1,64 IC95\% 1,19- 2,27). Verificou-se chance três vezes maior de violência episódica do que violência de repetição $(\mathrm{OR}=2,96)$. 
Tabela 3. Comparação dos tipos de violência segundo sexo, faixa etária, ocorrência em domicílio, agressão pelos filhos, consumo de bebida pelo agressor e caráter de repetição. Minas Gerais, 2011-2012

\begin{tabular}{|c|c|c|c|c|c|c|c|c|c|c|c|c|}
\hline \multirow[t]{2}{*}{ Variáveis } & \multicolumn{4}{|c|}{ Física } & \multicolumn{4}{|c|}{ Psicológica } & \multicolumn{4}{|c|}{ Negligência } \\
\hline & $\mathbf{N}$ & $\%$ & O.R & IC-95\% & $\mathbf{N}$ & $\%$ & O.R & IC-95\% & $\mathbf{N}$ & $\%$ & O.R & IC-95\% \\
\hline \multicolumn{13}{|l|}{ Sexo } \\
\hline Feminino & 731 & 75 & 1 & - & 362 & 39,8 & 1 & - & 126 & 13,80 & 1 & - \\
\hline Masculino & 702 & 87,9 & 2,31 & $(1,78 ; 2,99)$ & 155 & 21,7 & 0,42 & $(0,34 ; 0,52)$ & 75 & 10,50 & 0,73 & $(0,54 ; 0,99)$ \\
\hline \multicolumn{13}{|l|}{ Faixa etária } \\
\hline 80 anos ou mais & 166 & 62,9 & 1 & - & 98 & 39,4 & 1 & - & 86 & 34,1 & 1 & - \\
\hline 60 a 69 anos & 855 & 86,5 & 3,8 & $(2,79 ; 5,17)$ & 279 & 31,3 & 0,7 & $(0,53 ; 0,94)$ & 33 & 3,7 & 0,08 & $(0,05 ; 0,12)$ \\
\hline 70 a 79 anos & 412 & 80,6 & 2,46 & $(1,76 ; 3,43)$ & 140 & 29 & 0,63 & $(0,46 ; 0,87)$ & 82 & 16,7 & 0,39 & $(0,27 ; 0,55)$ \\
\hline \multicolumn{13}{|c|}{ Ocorrência em domicílio } \\
\hline Sim & 896 & 76,8 & 1 & - & 415 & 37,9 & 1 & - & 167 & 15,3 & 1 & - \\
\hline Não & 301 & 90,7 & 2,4 & $(1,98 ; 4,35)$ & 75 & 25,3 & 0,56 & $(0,43 ; 0,74)$ & 16 & 5,4 & 0,31 & $(0,17 ; 0,53)$ \\
\hline \multicolumn{13}{|c|}{ Agressão pelos filhos } \\
\hline Sim & 266 & 72,7 & 1 & - & 148 & 43,3 & 1 & - & 81 & 23,5 & 1 & - \\
\hline Não & 820 & 81 & 1,61 & $(1,22 ; 2012)$ & 306 & 30,5 & 0,58 & $(1,09 ; 0,74)$ & 71 & 7,1 & 0,25 & $(0,17 ; 0,35)$ \\
\hline \multicolumn{13}{|c|}{ Agressor consumiu bebida alcoólica } \\
\hline Não & 458 & 79,2 & 1 & - & 176 & 32,6 & 1 & - & 69 & 12,8 & 1 & - \\
\hline $\operatorname{Sim}$ & 426 & 86,2 & 1,64 & $(1,19 ; 2,27)$ & 183 & 40,6 & 1,41 & $(1,09 ; 1,83)$ & 29 & 6,5 & 0,47 & $(0,30 ; 0,75)$ \\
\hline \multicolumn{13}{|c|}{ Violência de repetição } \\
\hline Sim & 421 & 71,8 & 1 & - & 276 & 49,9 & 1 & - & 121 & 22,2 & 1 & - \\
\hline Não & 597 & 88,3 & 2,96 & $(2,20 ; 3,98)$ & 148 & 23,8 & 0,31 & $(0,24 ; 0,40)$ & 17 & 2,8 & 0,1 & $(0,06 ; 0,17)$ \\
\hline \multirow[t]{2}{*}{ Variáveis } & \multicolumn{4}{|c|}{ Sexual } & \multicolumn{4}{|c|}{ Financeira } & \multicolumn{4}{|c|}{ Autoprovocada } \\
\hline & $\mathbf{N}$ & $\%$ & O.R & IC-95\% & $\mathbf{N}$ & $\%$ & O.R & IC-95\% & $\mathbf{N}$ & $\%$ & O.R & IC-95\% \\
\hline \multicolumn{13}{|l|}{ Sexo } \\
\hline Feminino & 54 & 6,1 & 1 & - & 67 & 7,5 & 1 & - & 111 & 12,7 & 1 & - \\
\hline Masculino & 2 & 0,3 & 0,04 & $(0,01 ; 0,018)$ & 36 & 5,1 & 0,66 & $(0,44 ; 1,00)$ & 115 & 16,9 & 1,4 & $(1,06 ; 1,86)$ \\
\hline \multicolumn{13}{|l|}{ Faixa etária } \\
\hline 80 anos ou mais & 13 & 5,3 & 1 & - & 31 & 12,8 & 1 & - & 15 & 6,4 & 1 & - \\
\hline 60 a 69 anos & 29 & 3,3 & 0,61 & $(0,31 ; 1,19)$ & 44 & 5 & 0,36 & $(0,22 ; 0,58)$ & 151 & 17,5 & 3,1 & $(1,79 ; 5,38)$ \\
\hline 70 a 79 anos & 14 & 3 & 0,54 & $(0,25 ; 1,17)$ & 28 & 5,8 & 0,43 & $(0,25 ; 0,73)$ & 60 & 13,1 & 2,2 & $(1,22 ; 3,96)$ \\
\hline \multicolumn{13}{|c|}{ Ocorrência em domicílio } \\
\hline $\operatorname{Sim}$ & 39 & 3,7 & 1 & - & 89 & 8,3 & 1 & - & 182 & 16,6 & 1 & - \\
\hline Não & 12 & 4 & 1,11 & $(0,57 ; 2,15)$ & 10 & 3,4 & 0,39 & $(0,20 ; 0,75)$ & 23 & 7,7 & 0,42 & $(0,27 ; 0,66)$ \\
\hline
\end{tabular}


Tabela 3. (cont.)

\begin{tabular}{|c|c|c|c|c|c|c|c|c|c|c|c|c|}
\hline \multicolumn{13}{|c|}{ Agressão pelos filhos } \\
\hline Sim & 2 & 0,6 & 1 & - & 38 & 11,2 & 1 & - & 9 & 2,8 & 1 & - \\
\hline Não & 45 & 4,5 & 7,81 & $(1,88 ; 32,35)$ & 51 & 5,1 & 0,42 & $(0,27 ; 0,66)$ & 175 & 19,1 & 8,25 & $(4,17 ; 16,33)$ \\
\hline \multicolumn{13}{|c|}{ Agressor consumiu bebida alcoólica } \\
\hline Não & 16 & 3 & 1 & - & 33 & 6,2 & 1 & - & 116 & 21,7 & 1 & - \\
\hline Sim & 15 & 3,4 & 1,13 & $(0,55 ; 2,31)$ & 25 & 5,6 & 0,91 & $(0,53 ; 1,55)$ & 44 & 9,8 & 0,39 & $(0,27 ; 0,57)$ \\
\hline \multicolumn{13}{|c|}{ Violência de repetição } \\
\hline Sim & 10 & 1,9 & 1 & - & 62 & 11,6 & 1 & - & 49 & 8,9 & 1 & - \\
\hline Não & 38 & 6,1 & 3,38 & $(1,67 ; 6,84)$ & 23 & 3,7 & 0,29 & $(0,18 ; 0,48)$ & 116 & 18 & 2,25 & $(1,58 ; 3,21)$ \\
\hline
\end{tabular}

Fonte: Sinan, 201313.

Em relação à violência psicológica, verifica-se que a chance de um idoso do sexo masculino sofrer esse tipo de agressão é menor $(\mathrm{OR}=0,42 \mathrm{IC} 95 \%$ 0,34-0,52). Esse tipo de violência é mais frequente entre idosos com mais de 80 anos. Quanto ao local de ocorrência, a chance foi maior no domicílio. $\mathrm{O}$ agressor, em geral, é o(a) filho(a); e o consumo de bebida alcoólica aumentou a chance de violência (OR=1,41 IC95\%1,091,83). Nessa tipologia, a repetição do ato violento ocorreu três vezes mais do que o evento isolado.

Idosas foram mais negligenciadas, com gradiente positivo com o aumento da idade. Esse tipo de violência aconteceu de modo repetido, no domicílio, tendo como agressor o(a) filho(a) da vítima, porém o consumo de bebida alcoólica mostra-se negativamente associado à negligência $(\mathrm{OR}=0,47 \mathrm{IC} 95 \%$ 0,30-0,75).

Quanto à violência financeira, não se evidenciou diferença entre os sexos, mas o sexo masculino tendeu a ser menos afetado. Os mais velhos foram mais vulneráveis quando comparados aos idosos na faixa de 60-69 anos.
A chance foi maior no domicílio; os agressores mais frequentes foram os filhos da vítima e esse tipo de violência tendeu a se repetir.

A violência autoprovocada teve distribuição semelhante em homens e mulheres, diminuindo entre aqueles com 80 anos ou mais. Predominou no domicílio, sem a ajuda de terceiros. A chance de um idoso sofrer esse tipo de violência é maior quando ocorre de forma isolada $(\mathrm{OR}=2,25)$, sem repetição.

$\mathrm{Na}$ violência física, permaneceram positivamente associadas no modelo logístico: a vítima ser do sexo masculino, na faixa etária entre 60 a 69 anos, o agressor ter consumido bebida alcoólica e a agressão fora do domicílio. O homem idoso tem o dobro de chance de ter violação física. $\mathrm{O}$ idoso entre 60-69 anos tem chance $68 \%$ maior de ser agredido quando comparado àquele com mais de 70 anos. Esse tipo de violência ocorre três vezes mais fora do domicílio. O consumo de bebida alcoólica pelo agressor duplica a chance de violência. $\mathrm{O}$ modelo mostrou-se ajustado $(p=0,409)$ e explicou cerca de $12 \%$ da agressão física ao idoso. 
Tabela 4. Modelo logístico final para violência física. Minas Gerais, 2011-2012

\begin{tabular}{lccr}
\hline Variáveis & \multicolumn{3}{c}{ Modelo final } \\
\cline { 2 - 4 } & Valor-p & O.R & I.C. - 95\% \\
\hline Sexo masculino & 0,002 & 1,83 & {$[1,25 ; 2,69]$} \\
Idade 60 a 69 anos & 0,000 & 2,28 & {$[1,45 ; 3,61]$} \\
Domicílio = Não & 0,003 & 2,64 & {$[1,40 ; 4,99]$} \\
Consumo de álcool pelo agressor & 0,000 & 2,05 & {$[1,42 ; 2,97]$} \\
\hline
\end{tabular}

Nota: Hosmer-Lemeshow p:0,409.

\section{Discussão}

A violência contra a pessoa idosa apresenta grande complexidade e faz parte da violência social, expressando-se nas formas como a sociedade organiza suas relações de classe, de gênero, grupos etários, da construção da percepção da violência pelos significados atribuídos aos fatos que são reconhecidos como problemas"1.

Com o envelhecimento populacional, o reconhecimento dos idosos como sujeitos de direitos específicos vem ganhando visibilidade pelo estabelecimento de políticas públicas e de legislações para atender às demandas da terceira idade.

O Estatuto do Idoso prevê que os casos de suspeita ou confirmação de violência contra os idosos sejam objeto de notificação compulsória ${ }^{6}$, com a inclusão da violência na relação de doenças e agravos de notificação compulsória em todos os serviços de saúde ${ }^{7}$ e a ampliação do número de órgãos a serem oficiados. Entre os outros fatores que contribuíram para o aumento dos registros, podem-se incluir a extensão do conceito de maus-tratos para o termo violência, $\mathrm{o}$ anonimato da denúncia e a facilidade de ser feita por ligação telefônica ${ }^{16}$.

A introdução do Módulo Idoso do Disque 100 representou importante avanço na captação de denúncias. No entanto, é importante reconhecer que a existência de inconsistências desse banco de abrangência nacional impede análise mais aprofundada dos dados, inclusive com agregação da idade em 60 anos ou mais, o que não considera a heterogeneidade das situações que envolvem idosos vulneráveis nas diversas faixas etárias ${ }^{17}$.

A imprecisão das informações, o sub-registro e a falta de integração entre os bancos de dados contribuem para o velamento da violência contra a pessoa idosa. A desvalorização dos registros nas instituições públicas imprime a esse segmento da população mais um tipo de violência, a violência institucional ${ }^{18}$, além de desestimular a denúncia/notificação. Assim, o enfrentamento da violência resta prejudicado por falhas do próprio sistema de defesa e proteção de direitos da pessoa idosa, refletindo o descaso dos serviços, bem como a escassez e a descontinuidade das políticas públicas propostas para a pessoa idosa no Brasil.

O desconhecimento e o descaso para com várias formas de manifestação de violência contra a pessoa idosa, visíveis e invisíveis, insidiosas e silenciosas, entre elas, os abusos físicos, psicológico, sexual, abandono, negligência, abusos financeiros, autonegligência e violência autoinfligida com as quais a sociedade convive, resultam de múltiplos fatores. Os maus-tratos podem se expressar, também ${ }^{19}$, pela desconsideração, alienação das decisões e infantilização do idoso. O choque de gerações faz com que os mais jovens considerem a velhice como 'decadência'; e os idosos, 'descartáveis'20,21. A dificuldade ou opção do idoso de não expor as mazelas familiares pelo silêncio conta com a cumplicidade dos familiares ${ }^{5,14}$, especialmente no contexto de envelhecimento 
populacional acelerado, marcado pela desigualdade social, como no Brasil18.

As denúncias e notificações registradas no Disque 100 e no Sinan Net representam apenas algumas das muitas formas de maus-tratos que o idoso vivencia, tornando-os públicos. A notificação parte de uma decisão local, baseada na capacidade de atuação e resposta de cada município, sendo que a implantação da vigilância desse agravo também se dá de maneira heterogênea. Dada a variabilidade de serviços e estruturas existentes para o enfrentamento da violência contra idoso, não convém categorizar algumas regiões com maior número de casos notificados como as mais violentas; pois tal classificação pode ser fruto da melhor vigilância e da percepção sobre determinado evento. Muito provavelmente, o total de denúncias de casos de violência contra a pessoa idosa perante outros segmentos deve estar subestimado, o que pode ser atribuído aos significados e percepção da sociedade em relação aos idosos em situação de vulnerabilidade, variando de acordo com a cultura local nos diversos municípios e mesorregiões do estado ${ }^{18}$, bem como pelo desconhecimento sobre o fluxo de denúncia ou da pouca disponibilidade dos idosos para denunciar.

Os arranjos familiares e o lugar do idoso nessa família são influenciados por fatores demográficos e socioeconômicos e devem ser analisados nas situações de violência doméstica perpetrada contra a pessoa idosa. Em Minas Gerais, dados da Pesquisa por Amostras de Domicílios $^{18}$ mostraram que $45,5 \%$ dos idosos moravam em domicílios com outro adulto; $21,1 \%$ residiam com outro idoso; $17,2 \%$ com adulto ou criança e apenas $14,6 \%$ dos idosos moravam sozinhos. O contingente de mulheres longevas que moram no domicílio com filhos ou genros/noras foi de $24,1 \%$, quase o triplo do observado entre as idosas de 60 a 79 anos (6,9\%). Esses dados apontam ser frequente a coabitação de mais de uma geração, o que pode favorecer o conflito, além do cuidado.

Segundo a mesma pesquisa ${ }^{18}$, quase a totalidade das pessoas idosas (88,7\%) era o chefe do domicílio (65,9\%), sendo 80\% homens. Apenas entre idosas de 80 anos ou mais a proporção de chefes é maior (57,8\%), refletindo, possivelmente, maior viuvez feminina. $O$ rendimento médio mensal dos idosos é semelhante ao dos não idosos, entretanto, quando somados os rendimentos médios provenientes de todas as atividades laborais, a renda da pessoa idosa supera a dos mais jovens, independentemente do gênero. Além disso, observou-se que $84,9 \%$ dos indivíduos idosos habitam em domicílios próprios e já pagos.

Assim, embora a condição da pessoa idosa seja favorável, a despeito de ser chefe de família, de ter rendimento maior que os mais jovens, de ser o dono da residência, ela tem o seu direito violado e não denuncia o agressor por medo de perder o vínculo afetivo, quando o algoz é membro da família. As denúncias e notificações contabilizadas nos dois sistemas investigados confirmam a maior vulnerabilidade da população idosa do sexo feminino, indicando uma possível violência de gênero, que continua no envelhecimento. Todavia, há diferenças: nas notificações, as violências físicas, tortura e as autoprovocadas são mais significativas no sexo masculino, fato corroborado pelo estudo sobre notificações de violência contra idosos no Brasil ${ }^{5}$. Nas denúncias e notificações, o local de ocorrência com maior número de eventos é o domicílio; o filho é o principal agressor; e o consumo de álcool pelo agressor aparece como importante fator de risco em relação às situações de violência contra a pessoa idosa. A relação entre álcool e violência está amplamente demonstrada, e frequentemente associada a violências física, psicológica e negligência ${ }^{16}$.

As situações caracterizadas como violência no interior da família podem se apresentar combinadas com a omissão do Estado, no seu dever constitucional de amparo ao idoso, sendo difícil distinguir quando começa uma e quando termina outra. Como decorrência, aparece a criminalização isolada do familiar que agride ou negligencia, porém desvinculada de uma política social sistemática, reveladora da falta 
de comprometimento do poder público com a velhice fragilizada.

Em 2012, em Minas Gerais, o total das denúncias de violência contra pessoas idosas por ordem decrescente foi: negligência/abandono, psicológica/moral, financeira/econômica e física. Contudo, nas notificações realizadas nos serviços de saúde, a violência física é a mais prevalente, seguida da psicológica e da negligência, possivelmente pelo fato de a violência física ser o tipo mais fácil de ser detectado pelos profissionais ${ }^{16}$.

No mesmo ano, observa-se o incremento das lesões autoprovocadas que, contrariando o senso comum, afetam mais os homens no início de sua velhice. Essa tentativa de uma morte autoinfligida revela que, no percurso do ciclo vital, o envelhecimento e a doença fragilizam o modelo de masculinidade predominante, enquanto outros adultos vão assumindo funções de mando na sociedade e na família ${ }^{22}$. Tradicionalmente, dentro da divisão sexual do trabalho e das competências, a casa é o espaço feminino ou feminilizante, por isso o homem aposentado sofre ao ter de se limitar ao espaço da casa. Para os homens idosos, o principal fator associado ao suicídio é a perda de status que o trabalho ou o emprego confere, gerando uma sensação de ausência de lugar social. Assim, para Minayo, Meneghel e Cavalcant ${ }^{22}$, as tentativas de suicídio podem ser uma forma de a pessoa idosa encerrar seu sofrimento interior, considerando que diante das limitações do envelhecimento o idoso que valoriza sua independência e individualidade reluta perder sua autonomia e depender de familiares e/ou cuidadores, resultando em autoinfligir uma agressão 9 .

A violência contra a pessoa idosa apresenta grande complexidade em sua gênese; dessa forma, conhecer sua distribuição e fatores associados torna-se útil nos processos de promoção e prevenção da sua ocorrência. $\mathrm{O}$ aspecto que deveria ser considerado crucial para enfrentar o problema é a efetivação de uma política consistente e concreta de apoio ao idoso em situação de dependência, marcada pela ação combinada da família e do poder público ${ }^{23}$. Para que isso ocorra, é necessário fortalecer a rede de cuidados e os processos de captação de denúncias e notificações; harmonizar as informações e garantir agilidade na divulgação das informações, visando à proteção das vítimas.

Diferentemente de décadas atrás, hoje o envelhecimento é parte da agenda política internacional e nacional, mas ainda é necessário avançar muito nas políticas públicas. No Brasil, mais de $95 \%$ dos idosos residem com as famílias ou em suas próprias casas; assim, é preciso investir na redução da violência intrafamiliar, em especial, no que se refere à negligência, maior índice de violência detectado. O espaço familiar, portanto, merece ser priorizado, visto que, muitas vezes, a família não sabe, não pode ou não quer cuidar de seus idosos. A opção de criminalizar a negligência e o abandono familiar não resolve a falta de estruturas de apoio para cuidar dos velhos com dependência. Dessa maneira, o Estado viola os direitos dos idosos ao abandonar a família que realmente não tem como lidar com tal dependência, especialmente aquelas de baixa renda ${ }^{24}$.

Para muitos idosos, a discriminação, marginalização e/ou exclusão dentro da própria casa ainda são motivo de silêncio, permanecendo a situação velada no conluio familiar. O medo de denunciar envolve subjetividade, o imaginário, a precaução, o retraimento e a defesa. Intervir nessa forma de violência implica trabalhar as relações e denunciar a quebra de respeito e de proteção. No entanto, relatar esse evento traz, muitas vezes, um constrangimento público, revelando casos tão complexos de vulnerabilidades sociais e clínicas, que mesmo o trabalho intersetorial e interdisciplinar torna-se ineficaz ante a morosidade dos encaminhamentos nos órgãos públicos e a falta de uma rede de apoio social para esses idosos e essas famílias.

A escassez de recursos públicos para o cuidado da população idosa pode ser aferida pelo reduzido número de programas e suporte para as famílias que cuidam de pessoas idosas 
frágeis. Na maioria das vezes, mesmo com dificuldades econômicas e emocionais, os familiares são culpabilizados por não conseguirem cuidar adequadamente de seus idosos ${ }^{\mathbf{2 4}}$.

Como limitação do estudo, destaca-se a análise de dados secundários com sub-registros e inconsistências. Apesar do incremento de notificações e de denúncias nos dois anos analisados, ainda existem muitas incompletudes das variáveis, restringindo as análises de ocorrência segundo perfil socioeconômico e demográfico da população.

A comunicação da violência, na forma de denúncia ou de notificação, exigida em lei, deveria se constituir em uma medida que permitisse articulação e disponibilização de recursos públicos para promoção de ações e reconstrução de relações afetivas. No entanto, às vezes, a informação se limita aos aspectos burocráticos, ficando os casos notificados sem encaminhamentos. Urge fortalecer o sistema Viva e propiciar a interação dos diversos programas e setores - Assistência Social, Segurança Pública, Educação, Cidadania -, buscando construir fluxos e processos comuns de trabalho mais efetivos na defesa e proteção das pessoas idosas.

Romper o silêncio e revelar a violência em suas várias facetas, além de garantir estrutura para atender às solicitações denunciadas, torna-se fundamental. Conscientizar o idoso, a família, a sociedade e o poder público sobre a importância do resgate da cidadania da pessoa idosa sinaliza que, além da oportunidade dada a todos de viver mais, deve-se assegurar ao idoso o direito de viver melhor, com qualidade e dignidade. 


\section{Referências}

1. Lima-Costa MF, Veras R. Saúde pública e envelhecimento. Cad. Saúde Pública. 2003; 19(3):700-701.

2. Minayo MCS. Violência contra idosos: relevância para um velho problema. Cad. Saúde Pública. 2003; 19(3):783-791.

3. Moraes CL, Apratto Júnior PC, Reichenheim ME. Rompendo o silêncio e suas barreiras: um inquérito domiciliar sobre a violência doméstica contra idosos em área de abrangência do Programa Médico de Família de Niterói, Rio de Janeiro, Brasil. Cad. Saúde Pública. 2008; 24(10):2289-2300.

4. Brasil. Ministério da Saúde. Viva: vigilância de violências e acidentes, 2008 e 2009. Dep. de Análise de Situação de Saúde. Brasília, DF: MS; 2010.

5. Mascarenhas MDM, Andrade SSCA, Neves ACM, et al. Violência contra a pessoa idosa: análise das notificações realizadas no setor saúde Brasil, 2010. Ciênc. Saúde Colet. 2012; 17(9):2331-2341.

6. Brasil. Lei n ${ }^{0}$ 10.741. Dispõe sobre o Estatuto do Idoso e dá outras providências, de $1^{\circ}$ de outubro de 2003. Diário Oficial da União. 3 Out 2003.

7. Brasil. Portaria ${ }^{\circ}{ }^{104}$. Define as terminologias adotadas em legislação nacional, conforme disposto no Regulamento Sanitário Internacional 2005 (RSI2005), a relação de doenças, agravos e eventos em Saúde Pública de notificação compulsória em todo território nacional, de 25 de janeiro de 2011. Diário Oficial da União. 26 Jan 2011.

8. Faleiros VP, Rapozo JMT. Efetividade da rede de atenção à saúde e à assistência social à pessoa idosa na expressão de usuários e gestores - o caso de Boa Vista/ RR. Textos e Contextos. 2011 ago-dez; 10(2):356-370.

9. Wanderbroocke ACNS, Moré CLOO. Significados de violência familiar contra o idoso na perspectiva de profissionais da Atenção Primária à Saúde. Ciênc. Saúde Colet. 2012; 17(8):2095-2103.
10. Resende JP, Andrade MV. Crime Social, Castigo Social: Desigualdade de renda e taxas de criminalidade nos municípios Brasileiros. Est. Econ. 2011; 41(1):173195.

11. Espíndola CR, Blay SL. Prevalência de maus-tratos na terceira idade: revisão sistemática. Rev. Saúde Pública. 2007; 41(2):301-306.

12. Secretaria de Direitos Humanos da Presidência da República. Balanço 2012. Disque 100, Disque Direitos Humanos. Brasília, DF; 2013. [acesso em dezembro de 2013]. Disponível em: ww.mpap.mp.br/images/infancia/Disque_100_RELATÓRIO_FINAL.pdf.

13. Brasil. Ministério da Saúde. Secretaria de Vigilância em Saúde. Departamento de Vigilância de Doenças e Agravos não Transmissíveis e Promoção da Saúde. Sistema de Vigilância de Violências e Acidentes (Viva): 2009, 2010 e 2011. Brasília, DF: Ministério da Saúde; 2013.

14. Faleiros VP, Loureiro AML, Penso MA. O conluio do Silêncio: a violência intrafamiliar contra a pessoa idosa. São Paulo: Roca; 2009.

15. Saliba O, Garbin CAS, Garbin AJI, et al. Responsabilidade do profissional de saúde sobre a notificação de casos de violência doméstica. Rev Saúde Pública. 2007; 41(3):472-477.

16. Pasinato MT, Camarano AA, Machado L. Idosos vítimas de maus tratos domésticos: estudo exploratório das informações dos serviços de denúncias. Texto para Discussão 1200-IPEA; 2006 [acesso em 2018 jul 10]. Disponível em: http://www.ipea.gov.br/portal/images/stories/PDFs/TDs/td_1200.pdf.

17. Cavalcanti MLT, Souza ER. Percepções de gestores e profissionais de saúde sobre a atenção aos idosos vítimas de violências no município do Rio de Janeiro. Ciênc. Saúde Colet. 2010; 15(6):2699-2708.

18. Boletim Pad-MG. Perfil da população idosa de Minas Gerais. Boletim PAD-MG. 2014; 3(6):1-85. 
19. Castro VC, Rissardo LK, Carreira L. Violência contra os idosos brasileiros: uma análise das internações hospitalares. Rev. Bras. Enferm. 2018; 71(supl2):777785.

20. Motta AB. Envelhecimento e sentimento do corpo. In: Minayo MCS, Coimbra Junior CEA, organizadores. Antropologia, saúde e envelhecimento. Rio de Janeiro: Fiocruz; 2002. p. 37-50. (Antropologia \& Saúde Collection).

21. Debert GG. A reinvenção da velhice: socialização e processos de reprivatização do envelhecimento. São Paulo: EDUSP, 1999.
22. Minayo MCS, Meneghel SN, Cavalcante FG. Suicídio de homens idosos no Brasil. Ciênc. Saúde Colet. 2012; 17(10):2665-2674.

23. Lemos CES. Entre o Estado, as famílias e o mercado. Revista Sinais Sociais. 2013; 8(22):9-86.

24. Giacomin KC, Couto EC. O caráter simbólico dos direitos referentes à velhice na Constituição Federal e no Estatuto do Idoso. Rev. Kairós. 2013; 16(2):141-160.

Recebido em 06/08/2018

Aprovado em 25/11/2018

Conflito de interesses: inexistente

Suporte financeiro: não houve 